\title{
Predict Metal Toxicity and Water Quality Criteria of Different Types of Water Into Taihu Lake, China Using Biotic Ligand Model
}

\author{
Yuan Zhang ${ }^{1}$, Liwen Chen ${ }^{1,2}$, Jie Dai ${ }^{2} \&$ Tao $\mathrm{Yu}^{1}$ \\ 1 State Key Laboratory of Environment Criteria and Risk Assessment, Chinese Research Academy of \\ Environmental Sciences, China \\ ${ }^{2}$ College of Chemistry and Environmental Engineering, Yangtze University, China \\ Correspondence: Tao Yu, State Key Laboratory of Environment Criteria and Risk Assessment, Chinese Research \\ Academy of Environmental Sciences, Beijing 100012, China. E-mail: yutao0325@sina.com
}

Received: October 8, 2013 Accepted: October 28, 2013 Online Published: December 7, 2013

doi:10.5539/enrr.v4n1p10 URL: http://dx.doi.org/10.5539/enrr.v4n1p10

\begin{abstract}
The Biotic Ligand Model (BLM) is an important tool in predicting acute toxicity of metal to aquatic organisms. This study used the BLM to predict acute toxicity $\left(\mathrm{LC}_{50}\right.$, the lethal concentration for $50 \%$ of test organisms) of $\mathrm{Cu}$ and $\mathrm{Zn}$ to Daphnia magna, and to predict water quality criteria (WQC) for different types of water (river water, treated and untreated sewage, and rainwater) into Taihu Lake, an important drinking water source for millions of population. Their effects of metal toxicity on Taihu Lake were also explored. The results showed that Taihu Lake water had a relatively higher $\mathrm{LC}_{50}(\mathrm{Cu})$ value $(1.38 \pm 0.60 \mathrm{mg} / \mathrm{L})$ than other types of water except for untreated sewage $(2.25 \pm 2.13 \mathrm{mg} / \mathrm{L})$. Of these types of water, predicted $\mathrm{LC}_{50}$ value of $\mathrm{Cu}$ followed the order of untreated sewage $>$ rainwater $>$ Taihu Lake $>$ river water $>$ sewage effluent. In addition, acute toxicity of $\mathrm{Zn}$ followed the order of river water $>$ rainwater $>$ Taihu Lake $>$ sewage effluent $>$ untreated sewage. Comparison of the predicted WQC values with the Chinese National Water Quality Standard of Surface waters indicated that the existing standard for copper might over-protect the aquatic organisms in Taihu Lake. The correlation analysis showed that increased DOC (dissolved organic carbon) concentration resulted in a higher $\mathrm{LC}_{50}$ value due to complexation between metal and organic matters, which reduced $\mathrm{Cu}$ toxicity. A significant positive relationship existed between cation concentration and predicted $\mathrm{LC}_{50}$ value, also indicating that cation concentration may reduce metaltoxicity. The work provided basic data for the study of water effect ratio (WER) and for the establishment of China's own water quality critieria based on Chinese water environmental conditions.
\end{abstract}

Keywords: Biotic Ligand Model (BLM), Taihu Lake, $\mathrm{LC}_{50}$, metal acute toxicity, Water Quality Criteria (WQC)

\section{Introduction}

With the development of social economy and urbanization process in China, natural existance of heavy metals was altered and their concentrations have greatly increased in water environment. Bioaccumulation of heavy metals in organisms could be harmful to other high grade organisms by food chain ecosystem, eventually harmful to human health (Fan, 2002; Yu, 2012). The degree of toxicity to aquatic organisms depends not only on the concentration of metal, but also on water chemistry of the exposure conditions (Clifford \& McGeer, 2010). Researchers carrried out many toxicology tests in order to study the relationship between metal toxicity and water chemistry (Meyer, Santore, \& Bobbitt, 1999; Wang, 2011; Santore, 2002). BLM was therein developed from many toxicity tests determining the effect of metal on organisms in various waters. In the past three decades, the theory of BLM has developed in a variety of aspects.

BLM provides a scientific method for the assessment and prediction of metal toxicity to aquatic organisms. The conceptual framework of BLM for the chemical speciation and toxicity sub-models is an adaptation of the gill surface interaction model (GSIM) originally proposed by Pagenkopf (Pagenkopf, 1983) and metal-gill model suggested by Playle (Playle, Dixon, \& Burnison, 1993a; 1993b). The subsequent development of BLM is now termed the biotic ligand model (BLM) by Paquin (2000) and Di Toro and Allen (2000). The application of BLM to improve environmental regulations related to the effect of metal to aquatic organisms (Villavicencio, 2005). Until recently, BLM prediction for the acute effect of metals has been applied for fish (such as rainbow trout and fathead minnow (Santore, 2001a)), invertebrates (such as Daphnia magna (Santore, 2002; Heijerick, 2005)) and the alga Pseudokirchneriella subcaptitata (Heijerick, De Schamphelaere, \& Janssen, 2005). In order to protect 
the aquatic organisms, the U.S. Environmental Protection Agency (EPA) has recommended use of BLM in establishment of water quality criteria (WQC) for $\mathrm{Cu}$ (USEPA, 2007). And it is also recommended to revise water quality standard both in developed and developing countries (Feng, 2012a).

Since 2000, many countries (e.g., Australia, New Zealand, and the Netherlands) and Organizations (e.g., the European Union (EU) and World Health Organization) have also published or revised water quality criteria (Feng, 2012b). In recent years, Canada and the United States had taken step to apply this scientific tool into water quality criteria. Compared with developed countries, China began to establish its own WQC system only recently $(\mathrm{Wu}, 2010)$. Although Chinese government and scholars have realized the limitation of existing WQC that only based on total dissolved metal concentrations in the waters, the implementation of BLM in the establishment of WQC system in China still has a long way to go (Chen, 2011; Wu, 2011).

The lake of Taihu, located in the Yangtze River Delta, is a hypereutrophic lake (Zhang, Hu, \& Yu, 2012). It is the third largest freshwater lake in China, with the lake area of $2250 \mathrm{~km}^{2}$. Taihu Lake is shallow, with an average water depth of only $2 \mathrm{~m}$. It is important for a variety of purposes including drinking, fishing, recreation, agriculture, and industry for many local cities such as Wuxi and Suzhou (Yu, 2012). With the local socioeconomic development, the lake water is intensively affected by discharges of industrial and agricultural effluents, together with other artificial activities (Yu, 2012; Cui, Yan, \& Cheng, 2010).

The aim of this project is to describe the application of BLM for predicting the effects of different types of water on acute toxicity of metal and to explain how the discharges affect the water quality of Taihu Lake. Additionally, the study provides the basic data for the determination of WER and offers the basic date for the establishment of water quality criteria under the Chinese conditions.

\section{Materials and Methods}

\subsection{Sampling}

In the early November of 2012, fifteen sites were sampled in Taihu Lake and ambient water including sewage water (sewage effluent and untreated sewage), river water, rainwater and Taihu Lake water (Figure 1). Of the 15 sites, five sites (T1-T5) were located in different representative parts of the Westlake or Eastlake and two sites (R1-R2) were located in the Caoqiao River (the largest tributary of Taihu Lake). To explore the impact of water inputs on water quality of the lake, we sampled six sites in six sewage treatment plants (STP) around the Taihu Lake. We also collected rainwater that has direct effect on the lake. The point source discharge (W7) was untreated sewage directly discharged into the lake. At each site, we collected two parallel water samples at 1-1.5 $\mathrm{m}$ depth with depth-hydrophore. All water column samples for measurement of metal were stored in pre-cleaned polythene bottles with a drop of $1 \mathrm{~mol} \mathrm{HCl}$, and then transported at $4{ }^{\circ} \mathrm{C}$ for analysis in the laboratory. Water samples for TOC measurement were preserved in a refrigerator at $0-4{ }^{\circ} \mathrm{C}$ and taken back to the lab for analysis with 1-2 days.

\subsection{Sample Treatment and Measurement}

The collected water samples included Taihu Lake water, river water, and rainwater, treated and untreated sewage. Water quality parameters of above water samples such as $\mathrm{pH}$, water temperature, dissolved oxygen (DO), turbidity and conductivity were measured twice in situ with YSI multi-functional water quality parameter instrument. The instrument was calibrated against standard solution before use. In the laboratory, samples were filtered through $0.45 \mu \mathrm{m}$ filter membrane, and then analyzed with inductively coupled plasma-mass spectrometry (ICP-MS; Agilent 7500) with the detection limit of $\leq 0.05 \mu \mathrm{g} / \mathrm{L}$ for total concentration of $\mathrm{Cu}, \mathrm{Zn}, \mathrm{Ca}^{2+}, \mathrm{Mg}^{2+}$, $\mathrm{Na}^{+}$and $\mathrm{K}^{+}$. Anions in solution $\left(\mathrm{Cl}^{-}, \mathrm{SO}_{4}{ }^{2-}\right)$ and hardness were measured using the National Standard Method in China (GB11896-89, HJ/T342-2007, GB7477-87). Alkalinity was measured using the method of "Determination methods for examination of water and wastewater" (State Environmental Protection Administration (Fourth Edition, 2002), China). The dissolved organic carbon (DOC) of the water was analyzed with TOC analyzer $\left(\right.$ Shimadzu- $\left.\mathrm{V}_{\mathrm{CPH}}\right)$ after infiltration with $0.45 \mu \mathrm{m}$ membrane. All samples were tested twice, so each water column sample had four measured values for each parameter, based on whcih calculations and statistical analysis were conducted. The results (mean \pm standard deviation) were shown in Table 1.

\subsection{Data Treatment and Statistics}

Daphnia Magna was chosen as the predicted species because of its sensitivity to metals and it is an aboriginal species in Taihu Lake. BLM (Ver 2.2.3; http://www.hydroqual.com/blm) was used for predicting acute toxicity of copper and zinc to Daphnia magna. Measured water chemistry values were used as model inputs. Sulfide concentrations were below detection limit, so the default value of the model was input (Paquin, Santore, \& Mathew, 2007). 
Correlation analysis was conducted to determine the relationship between any two variables. Data calculation and statistics were performed with SPSS 16.0 (USA) software and Sigma Plot 10.0. Spatial distribution figure of sampling sites was performed with Golden Software Surfer 8.0.

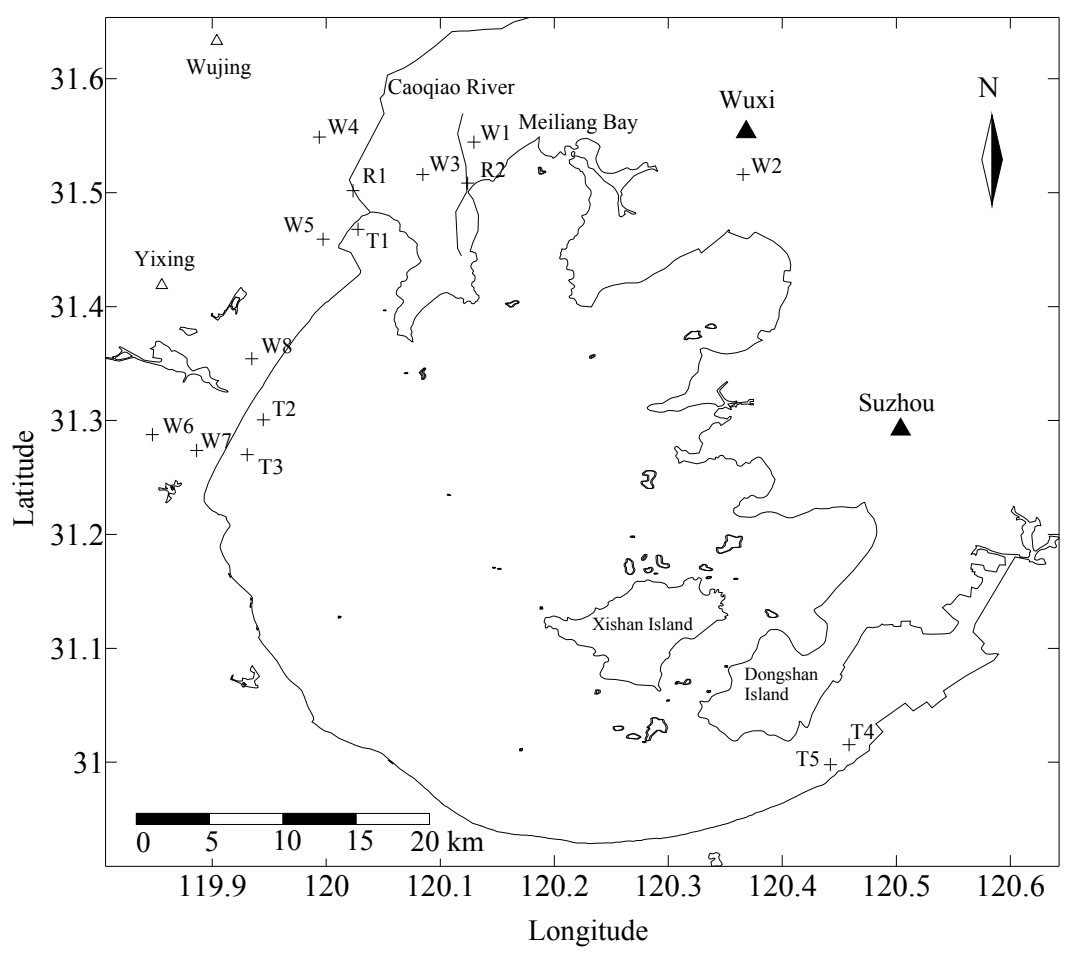

Figure 1. Sampling sites in the current study (Triangles sites, dots important cities near the lake; W1-W6 sites, six sewage treatment plants; W7 site, untreated sewage sampling point; W8 site, rainwater sampling point)

\section{Results and Discussion}

\subsection{Characterization of Waters Into Taihu Lake}

A summary of the analytical and statistical data for five types of water were presented in Table 1. The five types of water exhibited alkaline $\mathrm{pH}$ value in the range of 7.30 to 8.60 with an overall mean of 8.00 . The high mean value of $\mathrm{pH}$ (8.56) was found in Taihu Lake water. The DOC concentration of five types of water ranged from 14.97 to $154.25 \mathrm{mg} / \mathrm{L}$ with a mean of $35.33 \mathrm{mg} / \mathrm{L}$. The large variation of DOC concentration may be mainly attributed to artificial and industrial contamination prevailing in this area. The high mean value of DOC concentration $(62.29 \mathrm{mg} / \mathrm{L})$ was found in the untreated sewage, which collected from sewage treatment plants (STP) near Taihu Lake. Research indicated that urban wastewater was mainly from kitchen wastewater, flushing and washing wastewater (Hu \& Lian, 2012), containing high soluble nutrients and organic matters (OMs). We measured DOC to characterize OMs in the laboratory. The mean DOC concentration followed the order of untreated sewage $>$ rainwater $>$ Taihu Lake $>$ river water $>$ sewage effluent.

In this study, rainwater had the lowest mean value of cation concentration and anion concentration, and Taihu Lake followed by. Calcium concentration $(43.37 \pm 24.22 \mathrm{mg} / \mathrm{L})$ and sodium concentration $(122.32 \pm 96.87 \mathrm{mg} / \mathrm{L})$ of untreated sewage were higher than other four types of water. Sewage effluent had higher anion concentration, magnesium concentration $(7.86 \pm 1.85 \mathrm{mg} / \mathrm{L})$ and potassium concentration $(9.64 \pm 0.84 \mathrm{mg} / \mathrm{L})$ than untreated seage and other types of water. The mean value of alkalinity and hardness were in the order of untreated sewage $>$ sewage effluent $>$ river $>$ Taihu Lake $>$ rainwater. The values for most of the parameters in the rainwater were found to be much lower than the other types of water, which indicated that rainwater had less impacts compared with other types of water. High levels of TN and TP were generally found in untreated sewage (22.95 to 35.66 $\mathrm{mg} / \mathrm{L} ; 0.89$ to $2.49 \mathrm{mg} / \mathrm{L}$ ). After untreated sewage discharged into Taihu Lake, the high level of TN and TP contributed to high eutrophication level in Taihu Lake and impaired Taihu Lake ecological function. ANOVA also revealed significant spatial differences for alkalinity, hardness, sodium, total nitrogen (TN), total phosphorus 
(TP), $\mathrm{pH}$ and potassium $(p<0.05)$ but no significant differences for temperature. According to this work, Taihu Lake had lower water quality than the other three types of water with the exception of rainwater.

Table 1. Physicochemical water-quality parameters

\begin{tabular}{|c|c|c|c|c|c|c|c|}
\hline Sites & $\mathrm{T}\left({ }^{\circ} \mathrm{C}\right)$ & $\mathrm{pH}^{\mathrm{a}}$ & $\mathrm{TN}^{\mathrm{a}}, \mathrm{mg} / \mathrm{L}$ & $\mathrm{TP}^{\mathrm{a}}, \mathrm{mg} / \mathrm{L}$ & $\mathrm{DOC}^{\mathrm{a}}, \mathrm{mg} / \mathrm{L}$ & $\mathrm{Ca}^{2+\mathrm{a}}, \mathrm{mg} / \mathrm{L}$ & $\mathrm{Mg}^{2+\mathrm{a}}, \mathrm{mg} / \mathrm{L}$ \\
\hline Untreated sewage & 20.3 & $7.83 \pm 0.57$ & $27.65 \pm 4.70$ & $2.16 \pm 1.36$ & $62.29 \pm 49.73$ & $43.37 \pm 24.22$ & $7.86 \pm 1.85$ \\
\hline Sewage effluent & 21.0 & $7.48 \pm 0.44$ & $15.33 \pm 8.98$ & $0.28 \pm 0.18$ & $21.71 \pm 5.19$ & $41.26 \pm 10.75$ & $8.66 \pm 5.19$ \\
\hline Taihu Lake & 19.5 & $8.56 \pm 0.20$ & $2.84 \pm 1.85$ & $0.073 \pm 0.057$ & $27.96 \pm 9.41$ & $28.77 \pm 4.80$ & $6.12 \pm 0.56$ \\
\hline River water & 19.8 & $7.90 \pm 0.12$ & $7.35 \pm 2.67$ & $0.069 \pm 0.010$ & $27.34 \pm 0.34$ & $31.27 \pm 1.60$ & $6.35 \pm 0.33$ \\
\hline Rainwater & 20.2 & $8.10 \pm 0.18$ & $3.50 \pm 1.57$ & $0.050 \pm 0.011$ & $33.08 \pm 1.60$ & $4.51 \pm 0.88$ & $0.39 \pm 0.10$ \\
\hline Sites & $\mathrm{Na}^{+\mathrm{a}}, \mathrm{mg} / \mathrm{L}$ & $\mathrm{K}^{+\mathrm{a}}, \mathrm{mg} / \mathrm{L}$ & $\mathrm{SO}_{4}{ }^{2-\mathrm{a}}, \mathrm{mg} / \mathrm{L}$ & $\mathrm{Cl}^{-\mathrm{a}}, \mathrm{mg} / \mathrm{L}$ & $\mathrm{ALK}^{\mathrm{b}}, \mathrm{mgCaCO}_{3} / \mathrm{L}$ & Hardness $^{\mathrm{b}}, \mathrm{mg} / \mathrm{L}$ & $\mathrm{S}^{\mathrm{c}}, \mathrm{mg} / \mathrm{L}$ \\
\hline Untreated sewage & $122.32 \pm 96.87$ & $9.64 \pm 0.84$ & $92.71 \pm 80.89$ & $125.29 \pm 76.19$ & $343.71 \pm 97.76$ & $219.29 \pm 68.89$ & N.D \\
\hline Sewage effluent & $109.99 \pm 77.43$ & $10.15 \pm 3.54$ & $163.50 \pm 126.71$ & $150.67 \pm 78.01$ & $178.97 \pm 101.00$ & $210.33 \pm 41.18$ & N.D \\
\hline Taihu Lake & $38.30 \pm 7.40$ & $3.84 \pm 0.27$ & $70.00 \pm 13.66$ & $73.60 \pm 15.73$ & $95.32 \pm 12.61$ & $148.60 \pm 19.11$ & N.D \\
\hline River water & $41.53 \pm 8.55$ & $4.07 \pm 0.34$ & $86.00 \pm 19.63$ & $70.50 \pm 8.66$ & $161.50 \pm 12.12$ & $161.50 \pm 12.12$ & N.D \\
\hline Rainwater & $1.13 \pm 0.13$ & $0.64 \pm 0.14$ & $9.50 \pm 2.08$ & $1.28 \pm 0.61$ & $9.87 \pm 1.02$ & $27.97 \pm 3.57$ & N.D \\
\hline
\end{tabular}

${ }^{\mathrm{a}}$ Chemical parameters were presented as the mean \pm standard deviation.

${ }^{\mathrm{b}}$ Hardness and alkalinity determined as $\mathrm{mg} / \mathrm{L}$ as $\mathrm{CaCO}_{3}$.

${ }^{\mathrm{c}}$ Sulfide was not detected.
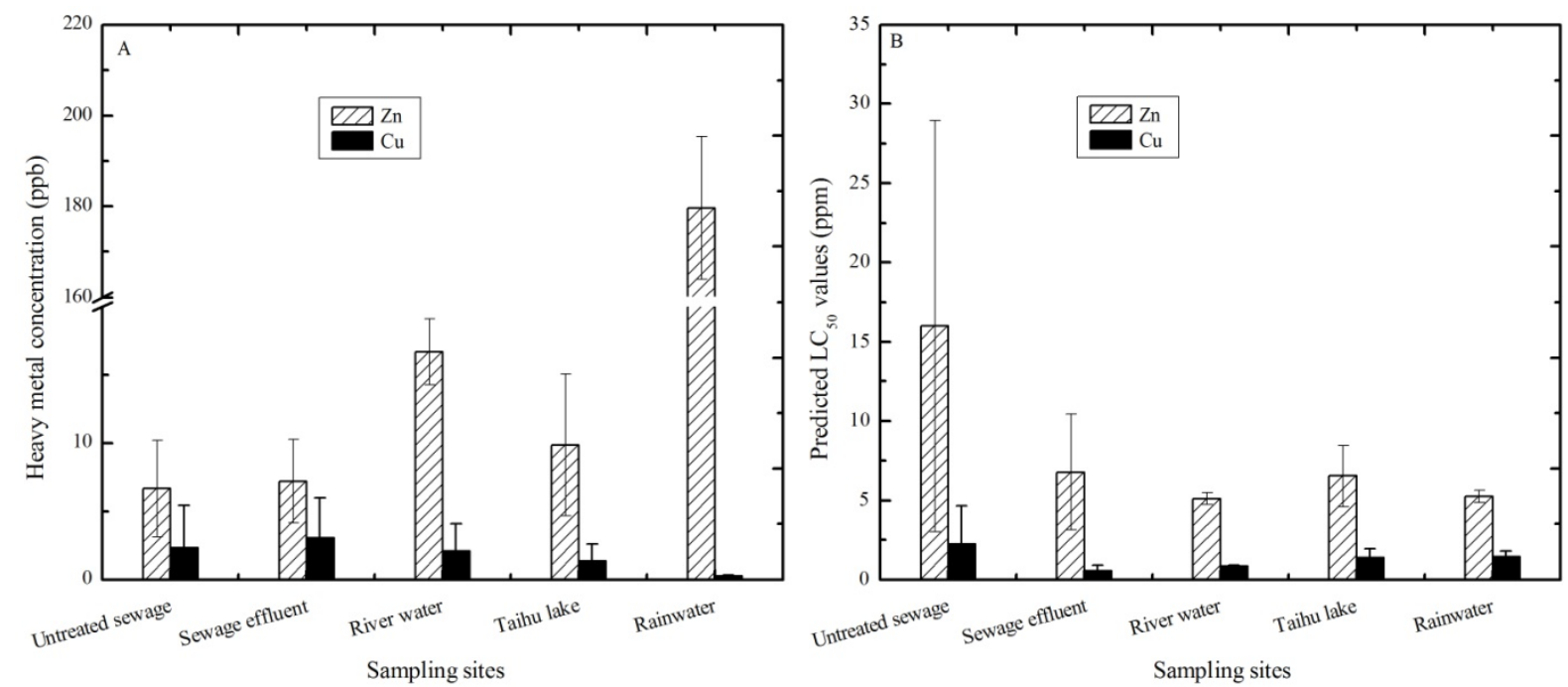

Figure 2. Metal concentration, predicted $\mathrm{LC}_{50}$ values of $\mathrm{Zn}$ and $\mathrm{Cu}$ in different types of water

\subsection{Predicted Acute Toxicity of Metals}

In this study, heavy metals $\mathrm{Cu}$ and $\mathrm{Zn}$ concentration in five types of water were in the range of 0.05 to $8.40,1.39$ to $200.5 \mu \mathrm{g} / \mathrm{L}$ with an overall mean of $1.91 \mu \mathrm{g} / \mathrm{L}$ and $32.15 \mu \mathrm{g} / \mathrm{L}$, respectively. Comparison with GB3838-2002 in China showed that concentration of copper was lower than the concentration standard, but the concentration of zinc was higher than the value of standard. The high mean value of $\mathrm{Zn}(179.70 \mu \mathrm{g} / \mathrm{L})$ was found at W8 (rainwater site) which had the lowest mean value of copper, because the specific climate conditions around Taihu Lake and the particulate matter in the atmospheric air. In addition, an insignificant relationship existed between metal concentration and predicted $\mathrm{LC}_{50}$ value (Figure 2). It was consistent with the research of Paquin (Paquin, Santore, \& Mathew, 2007). 
Inputed the data in Table 1 into BLM to assess the influence of the factors on metal toxicity and to predict $\mathrm{LC}_{50}$ value of metal $(\mathrm{Cu}$ and $\mathrm{Zn})$. Predicted $\mathrm{LC}_{50}$ values of $\mathrm{Cu}$ in five types of water ranged from 0.32 to $4.25 \mathrm{mg} / \mathrm{L}$ with an overall mean $1.33 \mathrm{mg} / \mathrm{L}$. The lowest mean value was showed for the sewage effluent. Taihu Lake had the medium value of predicted $\mathrm{Cu}_{\mathrm{LC}}$. Predicted $\mathrm{LC}_{50}$ values of $\mathrm{Zn}$ in all types of water were in the range of 3.38 to $35.15 \mathrm{mg} / \mathrm{L}$ with a mean of $8.72 \mathrm{mg} / \mathrm{L}$. The variation of predicted $\mathrm{LC}_{50}$ value of $\mathrm{Zn}$ mainly attributed to the difference of water quality between the five types of water. Predicted $\mathrm{LC}_{50}$ value of $\mathrm{Zn}$ were arranged in the order of untreated sewage $>$ sewage effluent $>$ Taihu Lake $>$ rainwater $>$ river water. The high mean values of predicted $\mathrm{LC}_{50}(\mathrm{Cu}$ and $\mathrm{Zn})$ were both found in untreated sewage which had high mean value of DOC concentration. In this study, predicted $\mathrm{LC}_{50}$ value of $\mathrm{Zn}$ was higher than the predicted $\mathrm{LC}_{50}$ value of $\mathrm{Cu}$ (Figure 2). The difference in the relative toxicity of zinc and copper was consistent with the finding in the study that gill binding constant for dissolved $\mathrm{Zn}$ was lower than that of dissolved $\mathrm{Cu}$ (Santore, 2001b). It was also consistent with the results of Galvez (1998) who had also measured a gill binding constant for zinc which was lower than the binding constants for copper as well (Yen, 2013).

\subsection{Predicted Water Quality Criteria}

The data in Table 1 were also used to determine the site-specific water quality criteria (WQC) for $\mathrm{Cu}$ in effluent-impacted Taihu Lake and ambient water. Predicted WQC value and the international WQC were showed in Figure 3. Comparison between predicted WQC and WQC published by the USEPA or calculated by Australia showed that the WQC values derived in the current study were noticeably different, one order of magnitude more than the WQC published by the USEPA or calculated by Australia. The difference between predicted WQC in the present study and those published by USEPA or calculated by Australia, probably because of two factors. Firstly, they have different organism species. Comparison between Taihu Lake and the Great Lakes in the United States indicated that Taihu Lake featured different geographical conditions and had different aquatic organisms (Wu, 2012). Secondly, different methods could lead to these differences. Additionally, WQC is affected by various environment factors, such as temperature, water hardness, dissolved oxygen, and organic matters etc. We also compared the predicted WQC values determined in the current study with the regulatory values defined in the National Water Quality Standard of Surface waters (GB 3838-2002 in China) indicated that the current standards for copper provided over-protection to aquatic life. In this study, the metal concentrations $(\mathrm{Zn}: 9.88 \pm 5.23 \mu \mathrm{g} / \mathrm{L}$, $\mathrm{Cu}: 2.08 \pm 2.03 \mu \mathrm{g} / \mathrm{L}$ ) of Taihu Lake were far less than the predicted WQC values (CMC: $430.25 \pm 207.12 \mu \mathrm{g} / \mathrm{L}$, CCC: $267.24 \pm 128.65 \mu \mathrm{g} / \mathrm{L}$ ), suggesting that Taihu Lake can protect the aquatic organisms. China attempts to develop water quality standard system, but has not comprehensive research on WQC systems so far. There is an urgent need to develop WQC system suitable for the regional of China by learning from proven international practices.

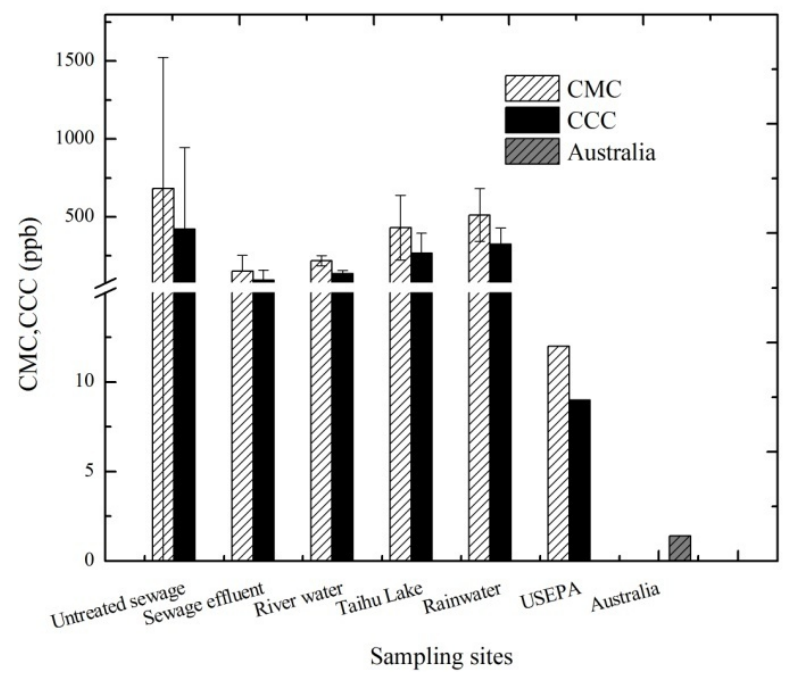

Figure 3. Comparison of predicted WQC value with international WQC 


\subsection{Effect of Water Parameters on Acute Metal Toxicity}

Table 2. The correlation between the predicted $\mathrm{LC}_{50}$ value, $\mathrm{CMC}$ values, $\mathrm{CCC}$ values and the chemistry parameters

\begin{tabular}{cccccccc}
\hline & $\mathrm{LC}_{50}(\mathrm{Cu})$ & $\mathrm{LC}_{50}(\mathrm{Zn})$ & $\mathrm{CMC}$ & $\mathrm{CCC}$ & $\mathrm{pH}$ & $\mathrm{DOC}$ & Alkalinity \\
\hline $\mathrm{LC}_{50}(\mathrm{Cu})$ & 1 & $0.905^{* *}$ & $0.973^{* *}$ & $0.973^{* *}$ & $0.331^{*}$ & $0.846^{* *}$ & $0.501^{* *}$ \\
$\mathrm{LC}_{50}(\mathrm{Zn})$ & $0.905^{* *}$ & 1 & $0.821^{* *}$ & $0.821^{* *}$ & 0.027 & $0.927^{* *}$ & $0.728^{* *}$ \\
$\mathrm{CMC}$ & $0.973^{* *}$ & $0.821^{* *}$ & 1 & $1.000^{* *}$ & $0.381^{*}$ & $0.756^{* *}$ & $0.396^{*}$ \\
$\mathrm{CCC}$ & $0.973^{* *}$ & $0.821^{* *}$ & $1.000^{* *}$ & 1 & $0.381^{*}$ & $0.756^{* *}$ & $0.396^{*}$ \\
\hline $\mathrm{LC} 50(\mathrm{Cu})$ & 0.242 & 0.051 & 0.164 & $0.428^{*}$ & 0.128 & 0.126 & 0.106 \\
$\mathrm{LC} 50(\mathrm{Zn})$ & $0.546^{* *}$ & $0.354^{*}$ & $0.499^{* *}$ & $0.739^{* *}$ & $0.423^{*}$ & $0.430^{* *}$ & $0.439^{* *}$ \\
$\mathrm{CMC}$ & 0.074 & -0.057 & -0.002 & 0.307 & 0.032 & 0.030 & -0.026 \\
$\mathrm{CCC}$ & 0.074 & -0.057 & -0.002 & 0.307 & 0.032 & 0.030 & -0.026 \\
\hline
\end{tabular}

${ }^{*}$ Correlation is significant at the 0.05 level (1-tailed).

${ }^{*}$ Correlation is significant at the 0.01 level (1-tailed).

Correlation analysis (Table 2) showed that significant relationship existed among predicted $\mathrm{Zn} \mathrm{LC}_{50}$ and chemical parameters except for $\mathrm{pH}$, indicating that almost all parameters had significant effects on $\mathrm{Zn}$ acute toxicity. But a significant effect of $\mathrm{pH}$ on $\mathrm{Cu}$ acute toxicity was also found. The effects of these water chemistry characteristics on metal acute toxicity were consistent with those found in previous researches (Santore, 2001b; Ryan, Tomasso, \& Klaine, 2009; Kozlova, Wood, \& McGeer, 2009). These studies indicated that the competition with cation $\left(\mathrm{Ca}^{2+}, \mathrm{Mg}^{2+}, \mathrm{K}^{+}\right.$and $\left.\mathrm{Na}^{+}\right)$could decrease the dissolved metal toxicity and the anions $\left(\mathrm{Cl}^{-}, \mathrm{SO}_{4}{ }^{2-}\right)$ could bind with the dissolved metal decrease the acute toxicity. Compared with the study of typical Chinese river (Wang, 2012), the chemistry parameters of Taihu Lake were significantly higher than typical rivers, especially DOC, alkalinity. These parameters seriously affect the metal acute toxicity. Thus, the predicted $\mathrm{LC}_{50}(1.38 \pm 0.59$ $\mathrm{mg} / \mathrm{L}$ ) value was higher than the Yellow River $(0.42 \mathrm{mg} / \mathrm{L}$ ) (Wang, 2012). Then the current study was suggestive of the importance of water chemistry on the bioavailability of metal in Taihu Lake, but a more systematic test for the effects of various water-chemistry characteristics on metal toxicity in freshwaters was necessary.

\subsubsection{Effect of DOC on Acute Metal Toxicity}

Correlation analysis showed that significant relationship existed between predicted $\mathrm{LC}_{50}$ value and $\mathrm{DOC}$ concentration, indicating that DOC concentration had highly significant effects on acute toxicity of metal. Meanwhile, a significant relationship existed among $\mathrm{CMC}, \mathrm{CCC}$ and $\mathrm{LC}_{50}$, DOC concentration (Table 2). A notable trend predicted $\mathrm{LC}_{50}$ value increased with the increase of DOC concentration. The magnitude sequence of zinc acute toxicity to Daphnia magna in different water was sewage effluent $>$ river water $>$ Taihu Lake $>$ rainwater $>$ untreated sewage (Figure 4A). This finding was in agreement with that for Lake Superior water (Erickson, Benoit, \& Mattson, 1987). In this study, untreated sewage, which had the highest DOC concentration that had the highest $\mathrm{LC}_{50}$ values for metals. The predicted $\mathrm{LC}_{50}$ increased in response to DOC addition because more Metal-DOC complexes resulted in reducing metal activity. Research showed that Zn-DOC complexes were dependant of the active sites of the organic matter (Liu, Wang, \& Tang, 1996). DOC also could directly bind with $\mathrm{Cu}$ and had a direct impact on prediction of metal acute toxicity (Kozlova, Wood, \& McGeer, 2009). Study indicated that if the presence of organic matters, almost all of the dissolved metal were present in the form of stable-species organic complexes without toxicity (Liu, Wang, \& Tang, 1996). After the treatment process of plants, the sewage effluent discharged into the river and it flowed through the river into the lake. The effluent also played a material role for water quality of Taihu Lake. Studies indicated that input of pollutants from the river was a major source of pollution in Taihu Lake (Yan, 2011). Taihu Lake sampling sites near the shore. The fishery activities and direct water (sewage effluent etc.) had significantly influences in Taihu Lake. 

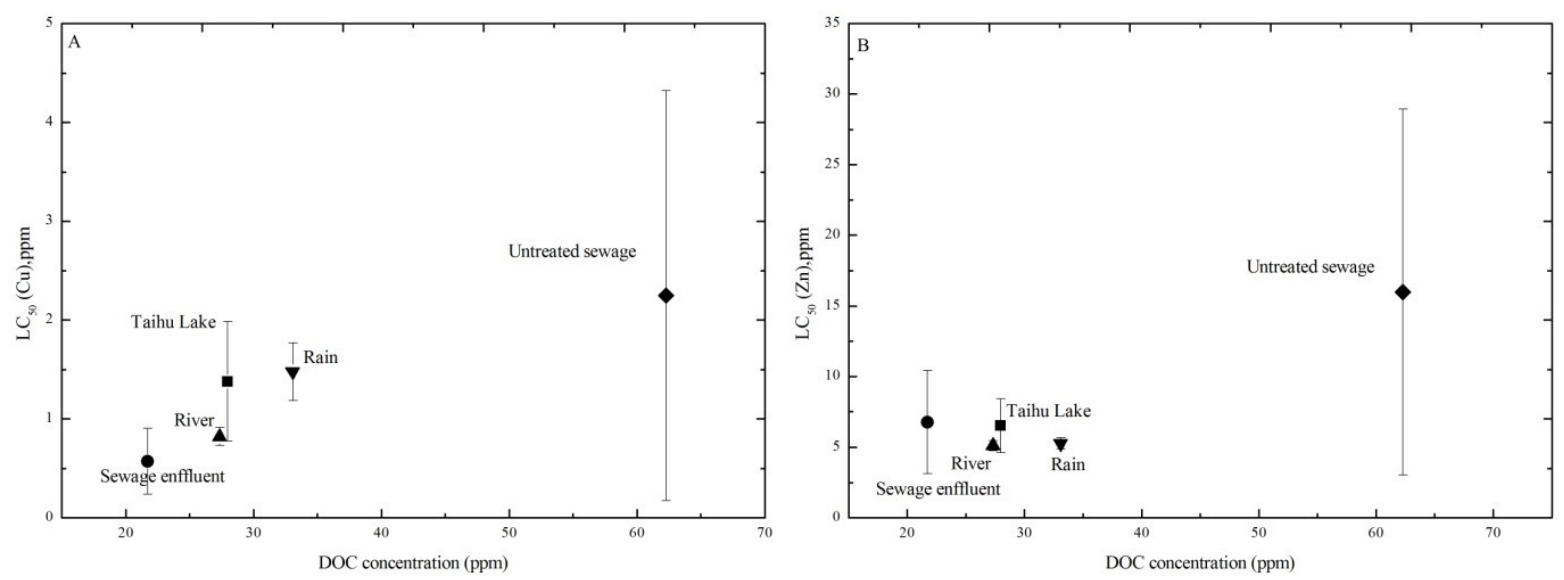

Figure 4. Effect of DOC on acute metal toxicity

\subsubsection{Effect of Alkalinity on Acute Metal Toxicity}

Correlation analysis also showed that significant relationship existed between predicted $\mathrm{LC}_{50}$ value and alkalinity, which indicated that alkalinity had an important effect on acute toxicity of metal. Untreated sewage had the highest predicted $\mathrm{LC}_{50}$ value $(\mathrm{Cu}$ and $\mathrm{Zn}$ ) which had the highest alkalinity (Figure 5). Metal could bind with several inorganic ligands, notably bicarbonate, carbonate, and hydroxide, and this reduced the metal toxicity markedly. In natural waters, metal bicarbonate complexes were dominant over the inorganic metal species (Paquin, Santore, \& Mathew, 2007). For this reason, untreated sewage, with higher bicarbonate concentration, presented higher $\mathrm{LC}_{50}$ values than other types of water. Sewage effluent had the lowest predicted $\mathrm{LC}_{50}(\mathrm{Cu})$ which had relatively high alkalinity value (Figure 5A). This finding indicated that alkalinity was not the leading factor to acute toxicity of metal. Taihu Lake had medium value of predicted $\mathrm{LC}_{50}(\mathrm{Cu}$ and $\mathrm{Zn})$ with medium value of alkalinity.
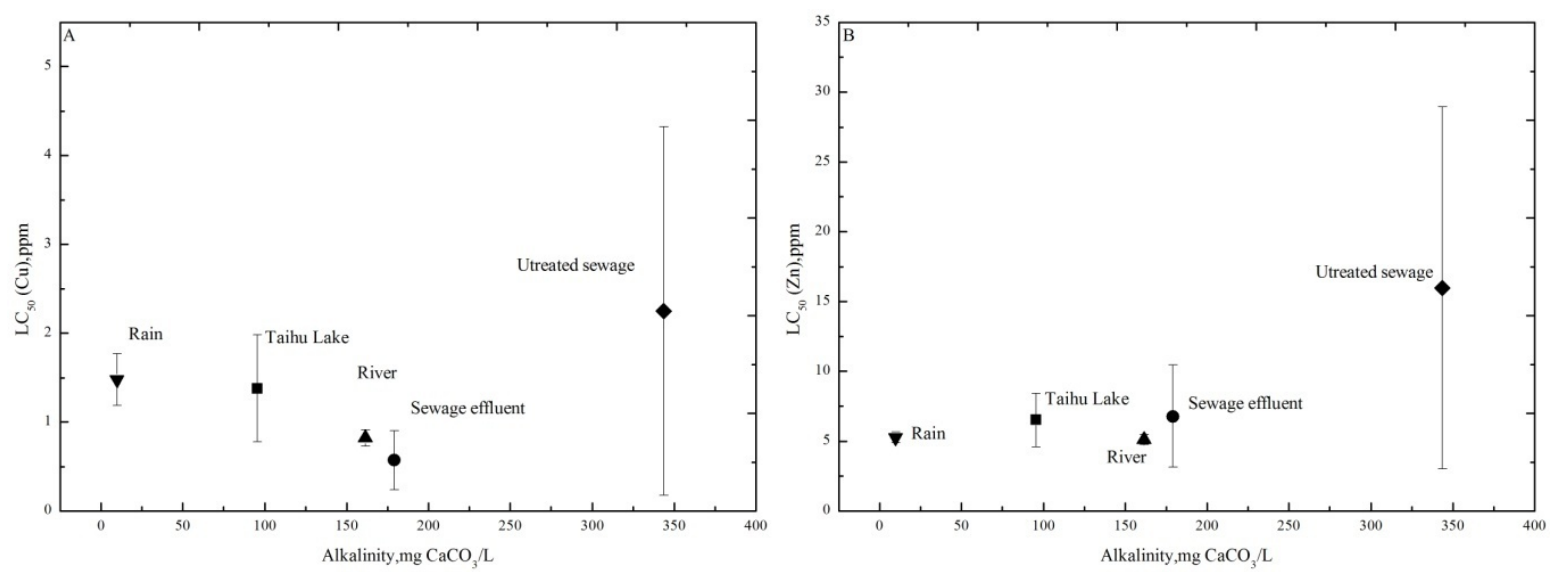

Figure 5. Effect of alkalinity on acute metal toxicity

\section{Conclusions}

The present work employed the BLM to predict acute toxicity of metal $(\mathrm{Cu}$ and $\mathrm{Zn})$ to Daphnia Magna in different types of filtered water collected from Taihu Lake and predict water quality criteria (WQC) for copper of different types of water into Taihu Lake. Taihu Lake had the medium value of predicted $\mathrm{Cu} \mathrm{LC}_{50}$ and predicted $\mathrm{Zn} \mathrm{LC}$ 50. DOC concentration was the most significant factor for acute toxicity of metal. Comparison of predicted WQC values determined in this study with the values defined in National Water Quality Standard of Surface waters of China (GB 3838-2002) indicated that the current standards for copper provided over-protection to aquatic organisms. The study also provided the basic data for the WER research and the establishment of water 
quality base for China's own conditions.

\section{Acknowledgements}

This work was financially supported by Water Special Project (2012ZX07506) and NSFC (21173026).

\section{References}

Chen, H. (2011). Dissolved organic carbon: a practical consideration in application of biotic ligand models in Chinese waters. Environ. Sci. Technol., 45(23), 9835-9836. http://dx.doi.org/10.1021/es203690w

Cheng, T., \& De Shamphelaere, K. (2005). Measurement and computation of zinc binding to natural dissolved organic matter in European surface waters. Anal. Chim. Acta., 542, 230-239. http://dx.doi.org/10.1016/j.aca.2005.03.053

Clifford, M., \& McGeer, J. C. (2010). Development of a biotic ligand model to predict the acute toxicity of cadmium to Daphnia pulex. Aquatic Toxicology, 98(1), 1-7. http://dx.doi.org/10.1016/j.aquatox.2010.01.001

Cui, Y., Yan, R., \& Cheng, W. (2010). Study on the Sewage Control Amount of Main Into-lake Rivers around Taihu Lake. Environmental Monitoring and Forewarning, 5, 34-39. http://dx.doi.org/10.3969/j.issm.1674-6732.2010.05.011

Di Toro, D. M., \& Allen, H. (2000). Biotic ligand model of the acute toxicity of metals. 1. Technical basis. Environ. Toxicol. Chem., 20, 2383-2396. http://dx.doi.org/10.1002/etc.5620201034

Erickson, R., Benoit, D., \& Mattson, V. (1987). A prototype toxicity factors model for site-specific copper water quality criteria.

Fan W. (2002). Recent Development in Bio-toxicological Assessment of Heavy Metal in Aquatic Sediments. Environmental Science \& Technology, 25(1), 36-39.

Feng, C. (2012a). Biotic Ligand Models for Metals: A Practical Application in the Revision of Water Quality Standards in China. Environmental Science \& Technology, 46, 10877-10878. http://dx.doi.org/10.1021/es303500n

Feng, C. (2012b). Water quality criteria research and progress. Science China Earth Sciences, 55(6), 882-891. http://dx.doi.org/10.1007/s11430-012-4384-5

Galvez, F. (1998). Zinc binding to the gills of rainbow trout: the effect of long-term exposure to sub-lethal zinc. Fish Biol., 52, 1089-1104. http://dx.doi.org/10.1111/j.1095-8649.1998.tb00957.x

Heijerick, D. G. (2005). Development of a chronic zinc biotic ligand model for Daphnia magna. Ecotoxicology and Environmental Safety, 62(1), 1-10. http://dx.doi.org/10.1016/j.ecoenv.2005.03.020

Heijerick, D. G., De Schamphelaere, K. A. C., \& Janssen, C. R. (2002). Biotic ligand model development predicting $\mathrm{Zn}$ toxicity to the alga Pseudokirchneriella subcapitata: possibilities and limitations, Comparative Biochemistry and Physiology Part C. Toxicology \& Pharmacology, 133(1-2), 207-218. http://dx.doi.org/10.1016/S1532-0456(02)00077-7

Hu, S., \& Lian, Z. (2012). Analysis of wastewater quality of residential areas in Chongqing. Environmental Science \& Technology, 35(8), 117-119. http://dx.doi.org/10.3969/j.issn.1003-6504.2012.08.026

Kozlova, T., Wood, C. M., \& McGeer, J. C. (2009). The effect of water chemistry on the acute toxicity of nickel to the cladoceran Daphnia pulex and the development of a biotic ligand model. Aquatic Toxicology, 91(3), 221-228. http://dx.doi.org/10.1016/j.aquatox.2008.11.005

Liu, Q., Wang, Z., \& Tang, H. (1996). Environmental Science, 17(1), 89-92.

Lv, Y. (2006). To predict copper toxicity in china 5 main rivers by using biotic ligand model. Acta Scientiae Circum stantiae, 26(12), 2080-2085.

Meyer, J. S., R. C., Santore, \& Bobbitt, J. P. (1999). Binding of Nickel and Copper to Fish Gills Predicts Toxicity When Water Hardness Varies, But Free-Ion Activity Does Not. Environmental Science \& Technology, 33, 913-916. http://dx.doi.org/10.1021/es980715q

Pagenkopf, G. (1983). Gill surface interaction model for tracemetal toxicity to fishes: Role of complexation, $\mathrm{pH}$, and water hardness. Environmental Science \& Technology, 17, 342-347. http://dx.doi.org/10.1021/es00112a007

Paquin, P. R. (2000). The biotic ligand model: a model of the acute toxicity of metals to aquatic life. Environmental Science \& Policy, 3, 175-182. http://dx.doi.org/10.1016/S1462-9011(00)00047-2 
Paquin, P., Santore, R., \& Mathew, R. (2007). Biotic Ligand Model windows interface, Version 2.2.3, user's guide and reference manual.

Playle, R. C., Dixon, D. G., \& Burnison, K. (1993a). Copper and Cadmium Binding to Fish Gills: Modification by Dissolved Organic Carbon and Synthetic Ligands. Canadian Journal of Fisheries and Aquatic Sciences, 50(a), 2667-2677.

Playle, R. C., Dixon, D. G., \& Burnison, K. (1993b). Copper and Cadmium Binding to Fish Gills: Estimates of Metal-gill Stability Constants and Modelling of Metal Accumulation. Canadian Journal of Fisheries and Aquatic Sciences, 50(b), 2678-2687.

Ryan, A. C., Tomasso, J. R., \& Klaine, S. J. (2009). Influence of pH, hardness, dissolved organic carbon concentration, and dissolved organic matter source on the acute toxicity of Copper to daphnia magna in soft waters implications for the Biotic Ligand Model. Environmental Toxicology and Chemistry, 28(8), 1663-1670. http://dx.doi.org/10.1897/08-361.1

Santore, R. C. (2001a). Biotic ligand model of the acute toxicity of metals. 2. Application to acute copper toxicity in freshwater fish and Daphnia. Environ. Toxicol. Chem., 20(10), 2397-2402. http://dx.doi.org/10.1002/etc.5620201035

Santore, R. C. (2001b). Biotic ligand model of the acute toxicity of metals. 2. Application to acute copper toxicity in freshwater fish and Daphnia. Environ. Toxicol. Chem., 20(10), 2397-2402. http://dx.doi.org/10.1002/etc.5620201035

Santore, R. C. (2002). Application of the biotic ligand model to predicting zinc toxicity to rainbow trout, fathead minnow, and Daphnia magna, Comparative Biochemistry and Physiology Part C. Toxicology \& Pharmacology, 133(1-2), 271-285. http://dx.doi.org/10.1016/S1532-0456(02)00106-0

USEPA. (2007). Aquatic life ambient freshwater quality criteria-copper.

Villavicencio, G. (2005). Biotic ligand model prediction of copper toxicity to daphnids in a range of natural waters in Chile. Environ. Toxicol. Chem., 24, 1287-2129. http://dx.doi.org/10.1897/04-095R.1

Wang, C. (2011). Application of the biotic ligand model to predict copper acute toxicity to Medaka fish in typical Chinese rivers. Water Sci Technol, 64(6), 1277-1283. http://dx.doi.org/10.2166/wst.2011.728

Wang, C. (2012). Application Research of Cu Toxicity and WQC Predicted by BLM in Typical Chinese Rivers. WuHan Unviersity.

Wu, F. (2010). China embarking on development of its own national water quality criteria system. Environ. Sci. Technol., 44(21), 7992-7993. http://dx.doi.org/10.1021/es1029365

Wu, F. (2011). Aquatic Life Ambient Freshwater Quality Criteria for Copper in China. Asian Journal of Ecotoxicology, 6, 617-628.

Wu, F. (2012). Derivation of water quality criteria for representative water-body pollutants in China. Science China Earth Sciences, 55(6), 900-906. http://dx.doi.org/10.1007/s11430-012-4424-1

Yan, S. (2011). Water quantity and pollutant fluxes of inflow and outflow rivers of Lake Taihu. Journal of Lake Sciences, 23(6), 855-862.

Yen, L. T. (2013). Modeling toxicity of binary metal mixtures $\left(\mathrm{Cu}^{2+}-\mathrm{Ag}^{+}, \mathrm{Cu}^{2+}-\mathrm{Zn}^{2+}\right)$ to lettuce, Lactuca sativa, with the biotic ligand model. Environ Toxicol Chem, 32(1), 137-43. http://dx.doi.org/10.1002/etc.2039

Yu, T. (2012). Distribution and bioaccumulation of heavy metals in aquatic organisms of different trophic levels and potential health risk assessment from Taihu lake, China. Ecotoxicology and Environmental Safety, 81, 55-64. http://dx.doi.org/10.1016/j.ecoenv.2012.04.014

Zhang, Y., Hu, X., \& Yu, T. (2012). Distribution and Risk Assessment of Metals in Sediments from Taihu Lake, China Using Multivariate Statistics and Multiple Tools. Bulletin of Environmental Contamination and Toxicology, 89(5), 1009-1015. http://dx.doi.org/10.1007/s00128-012-0784-7

\section{Copyrights}

Copyright for this article is retained by the author(s), with first publication rights granted to the journal.

This is an open-access article distributed under the terms and conditions of the Creative Commons Attribution license (http://creativecommons.org/licenses/by/3.0/). 